Results The results revealed that $71.1 \%$ of the concessions were denied and $28.9 \%$ were granted. It was showed divergent values between the medical evaluation with lower values (mean scores of 0.4 ) in the activity/participation domain compared with results of higher values obtained from the social assistants (mean scores of 3.0) for the same domain. These results were statistically significant with $\mathrm{p}<0.001$.

Discussion The results were divergent when comparing the evaluations made by the medical examiners and social workers. These results may help assist in a better understanding of the analysis of the ICF as an instrument for the evaluation of BPC. It is suggested the need of possibly better standardisation in the method of the ICF instrument application in order to minimise the divergence of results

\section{HEALTH PROBLEMS IN EARLY ADULTHOOD PREDICT DISABILITY RETIREMENT}

${ }^{1} \mathrm{H}$ Frilander*, ${ }^{1} \mathrm{~T}$ Lallukka, ${ }^{1} \mathrm{E}$ Viikari-Juntura, ${ }^{2} \mathrm{M}$ Heliövaara, ${ }^{1} \mathrm{~S}$ Solovieva. ${ }^{1}$ Finnish Institute of Occupational Health, Helsinki, Finland; ${ }^{2}$ National Institute for Health and Welfare, Helsinki, Finland

\subsection{6/oemed-2018-ICOHabstracts.1571}

Introduction Disability retirement causes a substantial burden on the society and affects the well-being of individuals. Early health problems as determinants of disability retirement have received little attention. The aim was to study, whether interrupting compulsory military service is an early indicator of disability retirement among Finnish men and whether seeking medical advice during military service increases the risk of allcause disability retirement and disability retirement due to mental disorders and musculoskeletal diseases. We also looked at secular trends in these associations.

Methods We examined a nationally representative sample of 2069 men, who had entered their compulsory military service during 1967-1996. We linked military service health records with cause-specific register data on disability retirement from 1968 to 2008. We explored secular trends in three service time strata. Cox regression model were used to estimate proportional hazard ratios and their 95\% confidence intervals.

Result During the follow-up time 140 (6.8\%) men retired due to disability, mental disorders being the most common cause. The men who interrupted service had a remarkably higher cumulative incidence of disability retirement (18.9\%). The associations between seeking medical advice during military service and all-cause disability retirement were similar across the three service time cohorts (overall hazard ratio 1.40 per one standard deviation of the number of visits; $95 \%$ confidence interval 1.26-1.56). Visits due to mental problems predicted disability retirement due to mental disorders in the men who served between 1987 and 1996 and a tendency for a similar cause-specific association was seen for musculoskeletal diseases in the men who served in 1967-1976.

Discussion Health problems, in particular mental problems, during late adolescence are strong determinants of disability retirement. Conscription examinations and military service provide access to the entire age cohort of men, where persons at risk for work disability can be identified and early preventive measures initiated.

\section{PEOPLE WITH DISABILITIES: PERCEIVED WORK EXPERIENCE AND HEALTH CONSEQUENCES}

${ }^{1}$ Andréia de Conto Garbin*, ${ }^{2}$ Frida Marina Fischer. ${ }^{1}$ Pontifical Catholic University of São Paulo and Mackenzie Presbyterian University, São Paulo São Paulo, Brazil; ${ }^{2}$ Department of Environmental Health, School of Public Health, University of São Paulo, São Paulo, Brazil

\subsection{6/oemed-2018-ICOHabstracts. 1572}

Introduction Brazilian private and public employers must reserve jobs to hire persons with disabilities. The inclusion operates precariously. Often employees are required to work in low skills jobs following taylorism-fordism or toyotism production modes. This study aimed to investigate perceived job experiences of workers with disabilities and impact on health. Methods This is a qualitative case study carried in São Paulo, Brazil. Focus groups (6) and interviews (4) with people with physical disabilities and deaf were performed. Physical disabilities were acquired in some cases as a result of work injuries, due to unsafe work conditions, and the perversity of the system projecting the worker to a condition of disabled person.

Results It prevails the discourse of disabled workers with unqualified skills. It is sought to include those who depend on few adaptations of the work environment. The requirements for professional qualification are based on the ideology of adjustment'. It becomes effective as inclusion programs aim to discipline behaviours, organisers of social life. These are requirements regarding subjectivity, modes of living, with emphasis on individual persistence and overcoming difficulties. Subtle control operates through the discourse of inclusion and the worker acquires the condition of reification.

Discussion Nowadays the deaf are limited in the use of their main mode of communication, the hands. There is a discourse in the companies about the 'productive deaf' reproducing the cultural isolation of the deaf people. The excluded, disguised as included, experience suffering related to social injustices and psychological violence. Regarding the work injuries, the degradation and precariousness of work generate a subpopulation of persons with disabilities, but denies them access to an effective rehabilitation system. Public policies should prevent the production of a double discrimination. It is also necessary to change the common speech labelling the disabled person as a disqualified professional.

\section{PREDICTING LONG-TERM SICKNESS ABSENCE AND SUPPORTING RETURN-TO WORK PROCESSES USING QUESTIONNAIRES}

${ }^{1} \mathrm{~K}$ Goorts ${ }^{*},{ }^{2,3} \mathrm{D}$ Rusu, ${ }^{1} \mathrm{M}$ Du Bois, ${ }^{1,4} \mathrm{~S}$ Vandenbroeck, ${ }^{4} \mathrm{C}$ Duchesnes, ${ }^{2} \mathrm{PH}$ Mairiaux, ${ }^{5} \mathrm{~S}$ Decuman, ${ }^{1,4} \mathrm{~L}$ Godderis. ${ }^{1}$ Katholieke Universiteit Leuven, Leuven, Belgium; ${ }^{2}$ Université de Liège, Belgium; ${ }^{3}$ SPMT-ARISTA, Brussels, Belgium; ${ }^{4}$ Idewe, Heverlee, Belgium; ${ }^{5}$ RIZIV, Brussels, Belgium

\subsection{6/oemed-2018-ICOHabstracts. 1573}

Introduction Promoting good health and attendance, instead of penalising absence, has become a growing policy issue, since long-term sickness absence is increasing in 27 European member states and Norway. As most employees will return to work spontaneously, resources for return to work projects should be dedicated to the high-risk group for long-term sickness absence. 